\title{
PELATIHAN PENINGKATAN KAPASITAS STAKEHOLDER DALAM MENYUSUN STRATEGI CITY BRANDING
}

\author{
Prima Mulyasari Agustini ${ }^{1 *}$, Tuti Widiastuti ${ }^{1}$, \\ ${ }^{1}$ Program Studi Ilmu Komunikasi, Fakultas Ekonomi dan Ilmu Sosial, Universitas Bakrie, Indonesia \\ E-mail: prima.agustini@bakrie.ac.id*, tuti.widiastuti@bakrie.ac.id \\ Received: March 12, 2020 / Revised: October 9, 2020 / Accepted: December 25, 2020 \\ DOI: https://doi.org/10.36782/ijsr.v2i2.26
}

\begin{abstract}
ABSTRAK
Merek adalah sebuah konsep yang penting dalam pemasaran produk, baik barang maupun jasa. Pemberian merek suatu kota diperlukan untuk memberikan identitas bagi kota tersebut. Dengan merek yang kuat suatu kota bisa "menjual dirinya" dan membuka lapangan kerja yang lebih luas, baik melalui keunggulan pariwisata seperti: kuliner, obyek wisata, kerajinan, atau seni budaya, sebagai pusat pendidikan, maupun keunggulan industri yang berpotensi menarik minat investor dalam dan luar negeri. Aceh yang diberitakan lekat dengan nilai-nilai Islami seringkali menjadikan kota ini tidak layak menjadi destinasi wisata. Dengan menggalakan pariwisata Islami, hingga saat ini Aceh masih kurang jumlah kunjungan wisatawannya, padahal budaya dan destinasi wisata Aceh banyak yang menarik untuk dikunjungi. Menilik pentingnya mengkomunikasikan keunggulan destinasi wisata Aceh, maka diperlukan pelatihan peningkatan kapasitas stakeholder dalam menyusun strategi city branding. Stakeholder mempunyai peran penting dalam mempromosikan citra kota, khususnya melalui berbagai media. Pelatihan ini berfokus dalam memberikan wawasan dan pengetahuan, serta keterampilan dalam menyusun strategi city branding yang menarik dan efektif melalui berbagai media untuk mengkomunikasikan citra Kota Banda Aceh.
\end{abstract}

Kata kunci: Citra Kota, City Branding, Kota Banda Aceh, Stakeholder, Strategi.

\begin{abstract}
Brand is an important concept in the marketing of products, booth goods and services. Giving a city a brand is needed to provide an identity for the city. With a strong brand, a city can "sell itself" and open up more extensive employment opportunities, both through tourism excellence (culinary, tourism, handicraft, arts, and culture), as an education center, as well as industry excellence that has the potential to attract investors inside and outside country. Banda Aceh, which is reported strictly with Islamic values, often makes this city unworthy of being a tourist destination. By promoting Islamic tourism, Banda Aceh still lacks in tourist arrivals, though many of Banda Aceh's culture and tourist destinations are fascinating to visit. Given the importance of communicating the superiority of destination related to Banda Aceh, stakeholder training needs to be developed in developing a city branding strategy. Stakeholders have an essential role in promoting the image of the city, primarily through various media. This training focuses on providing insights and knowledge, as well as skills in developing attractive and effective city branding strategies through multiple media to communicate the image of Banda Aceh.
\end{abstract}

Keywords: Banda Aceh, City Branding, City Image, Stakeholder, Strategy. 


\section{PENDAHULUAN}

Merek adalah sebuah konsep penting dalam pemasaran sebuah produk. Upaya pemberian merek atau branding bisa dilakukan baik untuk komponen yang bersifat tangible (kasat mata) seperti nama, logo dan kemasan maupun yang bersifat intangible (tidak kasat mata) seperti suasana dan citra. Lebih jauh lagi, konsep merek tidak hanya dapat diimplementasikan pada suatu produk atau jasa, namun juga dapat diimplementasikan untuk suatu wilayah. Cakupan wilayah tersebut bisa dalam batas negara, kepulauan, provinsi maupun kota dan kabupaten.

Pemberian merek suatu kota diperlukan untuk memberikan identitas bagi kota tersebut. Dengan adanya identitas, maka kota akan memiliki ciri khas tersendiri yang idealnya tidak dimiliki oleh kota lain. Kota yang tidak memiliki keunikan tidak akan diingat, tidak memiliki diferensiasi dan tidak akan bisa bersaing dengan kota lain. Dengan merek yang kuat suatu kota bisa "menjual dirinya" dan membuka lapangan kerja yang lebih luas, baik melalui keunggulan pariwisata (kuliner, obyek wisata, kerajinan, atau seni budaya), sebagai pusat pendidikan, maupun keunggulan industri yang berpotensi menarik minat investor dari dalam maupun luar negeri. Dampaknya akan berpengaruh pada peningkatan Pendapatan Asli Daerah (PAD) dan kesejahteraan warga. Pakar perilaku konsumen dan studi etnografi, Maulana (2012), menyatakan bahwa merek yang kuat memiliki tiga komponen penting yaitu relevan, dimana merek harus sesuai dengan kebutuhan dan keinginan konsumen atau pemangku kepentingan (stakeholder). Merek juga harus distinctive, yaitu mampu menonjolkan keunikannya yang berbeda dari kompetitornya. Ketiga, merek harus konsisten yaitu merek harus mampu mengoptimalkan dan mengelola keunikan yang "dijual" sehingga akan selalu terpatri di benak konsumen (Maulana, 2012).

Proses penciptaan merek suatu wilayah bukanlah proses sederhana yang dapat dilakukan dalam waktu singkat. Diperlukan pemahaman yang komprehensif mengenai dinamika suatu kota yang tercipta dari interaksi antara masyarakat, pemerintah, pelaku industri, pendatang dan pemangku kepentingan lain. Pemetaan terhadap pemangku kepentingan penting dilakukan untuk mengetahui dan menggali persepsi, harapan, rasa memiliki dan tanggung jawab terhadap keberlangsungan dan pengembangan kota. Di samping itu potensi kota dari sisi sumber daya alam dan budaya masyarakat setempat juga harus digali, sebelum akhirnya dapat menetapkan keunikan yang dapat diolah untuk dijadikan merek suatu kota. Namun, Banda Aceh belum mengoptimalkan potensi dari produk unggulan daerahnya untuk mengangkat citra kota dan membangun city branding yang positif.

Sebuah kota/kabupaten memiliki program unggulan yang perlu dikomunikasikan kepada para pemangku kepentingan, sehingga 
diperlukan kapabilitas komunikator dalam berkomunikasi, baik dalam bentuk personal, kelompok maupun bermedia, baik on line maupun off line. Kegiatan komunikasi tentang kota/kabupaten perlu dilakukan secara masif, agar eksistensi sebuah kota/kabupaten dapat dirasakan oleh stakeholder. Lebih jauh, diharapkan hasil komunikasi ini dapat membawa perubahan kognisi, afeksi maupun behavioral, sehingga akan menimbulkan kecintaan dan kemenarikan wilayah bagi pihak lain. Selain itu, tentu akan terbentuk kota/kabupaten dengan citra yang baik.

Citra kota itu sifatnya abstrak, berada dalam pikiran stakeholder. Citra dapat dirasakan, dari hasil penilaian baik atau buruk, seperti penerimaan dan tanggapan positif maupun negatif yang datang dari stakeholder. Citra pada dasarnya bisa diketahui, diukur dan diubah, walaupun perubahannya relatif lambat. Dengan kata lain, suatu citra akan bertahan cukup permanen pada kurun waktu tertentu.

Dalam pembangunan identitas kota diperlukan strategi city branding yang terencana dengan baik dan perlu partisipasi dari pemerintah daerah atau dinas terkait juga masyarakat. Sejalan dengan kajian yang dilakukan Hartono, Safitri dan Kurnianingsih (2019), bahwa proses membangun image kota atau destinasi wisata perlu perencanaan dan pengembangan wilayah wisata yang mengerahkan daya upaya pemerintah daerah, dinas pariwisata, juga masyarakat.
Pendayagunaan kapasitas stakeholder terkait city branding sangatlah penting agar dapat mengelola identitas kotanya dengan baik.

Kota Banda Aceh memiliki keberagaman suku, agama, budaya dan ras, yang menjadi potensi untuk dibentuk menjadi identitas kota dan daya tarik bagi wisatawan untuk mengunjunginya. Selain memiliki potensi, di sisi lain Kota Banda Aceh juga memiliki beberapa kelemahan pada sektor pariwisata, dimana secara geografis, kota ini bukan merupakan jalur transit, dinilai secara demografis sebagai kota dengan penduduk yang fanatik dengan syariat Islam juga masih kurangnya infrastruktur pendukung. Saleh dan Anisah (2020), dalam kajiannya mengenai Pariwisata Halal di Aceh: gagasan dan Realitas Lapangan juga menyatakan bahwa faktor komitmen investasi pemerintah dan swasta pun masih kurang.

Subarkah, dkk. (2020), dalam kajiannya mengenai Destination Branding Indonesia sebagai Destinasi Wisata Halal, menyatakan bahwa Indonesia melakukan destination branding dengan menetapkan logo Halal Tourism Indonesia, dan menunjuk tiga daerah yang siap menjadi destinasi wisata halal unggulan yakni Lombok, Aceh dan Sumatera Barat. Dengan adanya kebijakan ini, maka Kota Banda Aceh mesti bersiap untuk menunjukan identitasnya dan menarasikan keunggulannya.

Menilik pentingnya mengkomunikasikan keunggulan daerah terkait Kota Banda Aceh, maka diperlukan pelatihan peningkatan 
kapasitas stakeholder dalam menyusun strategi city branding. Stakeholder mempunyai peran penting dalam mempromosikan citra kota, khususnya melalui berbagai media.

\section{TINJAUAN PUSTAKA}

\section{A. City Branding Communication Model}

Sukmaraga dan Nirwama (2016), dalam kajiannya mengenai City Branding: Sebuah Tinjuan Metodologis dengan Pendekatan Elaboratif, Praktis, dan IImiah, yang menyatakan bahwa city branding dipahami sebagai jaringan asosiasi atau persepsi di dalam benak konsumen yang didasarkan pada aspek visual, verbal serta ekspresi behavioral dari suatu tempat, yang diwujudkan melalui tujuan, komunikasi, nilainilai dan budaya umum stakeholder, serta desain kota secara holistik. Kajian ini juga memberikan pendekatan lima langkah dalam city branding yaitu: (1) menentukan nilai merek inti kota, (2) menentukan pesan merek inti kota, (3) menentukan kepribadian kota, (4) menentukan ikon merek kota, dan (5) perancangan peta jalan merek. Dengan melibatkan stakeholder internal akan dapat dijabarkan nilai-nilai potensial yang dimiliki kota. Analisis perlu dilakukan dengan melihat kesenjangan antara persepsi masyarakat mengenai kota dan realitas kota yang ada. Dengan cara ini, dapat ditenrukan segmentasi, targeting dan positioning identitas kota. Kajian yang dilakukan melalui stakeholder internal akan dapat memetakan kepribadian atau identitas yang potensial bagi kota, yang selanjutnya dapat ditentukan kepribadian atau identitas intinya. Luaran city branding dapat berupa ikon dan makna tanda. Dalam pengembangan city branding diperlukan peta jalan brand. Tujuannya adalah adanya konsistensi antara tahapantahapan city branding yang telah dilakukan. Oleh karena itu, pembuatan panduan dalam roadmap city branding menjadi aspek penting.

Menurut Sinholt dalam Moilanen dan Rainisto (2009), city branding adalah manajemen citra suatu destinasi melalui inovasi strategis serta koordinasi ekonomi, sosial, komersial, kultural, dan pengaturan pemerintah. Chaniago (dalam Yuli, 2011), mengemukakan bahwa City Branding adalah proses atau usaha membentuk merek dari suatu kota untuk mempermudah pemilik kota tersebut memperkenalkan kotanya kepada target pasar (investor, tourist, talent, event) kota tersebut dengan menggunakan kalimat positioning, slogan ikon, eksibisi, dan berbagai media lainnya.

Proses penciptaan merek tidak dapat dipisahkan dari aktivitas komunikasi yang terkait dengan atribut multi dimensional seperti elemen fungsional, emosional, relasional dan stratejik, seperti yang dikemukakan oleh Louro dan Cunha (dalam López, et.al, 2016). Mengenai bagaimana proses komunikasi merek untuk suatu kota, Kavaratzis (2014), memperkenalkan sebuah model, yaitu City Branding Communication Model. 
Dalam model ini Kavaratzis mengemukakan aktivitas - aktivitas komunikasi yang membentuk citra kota.

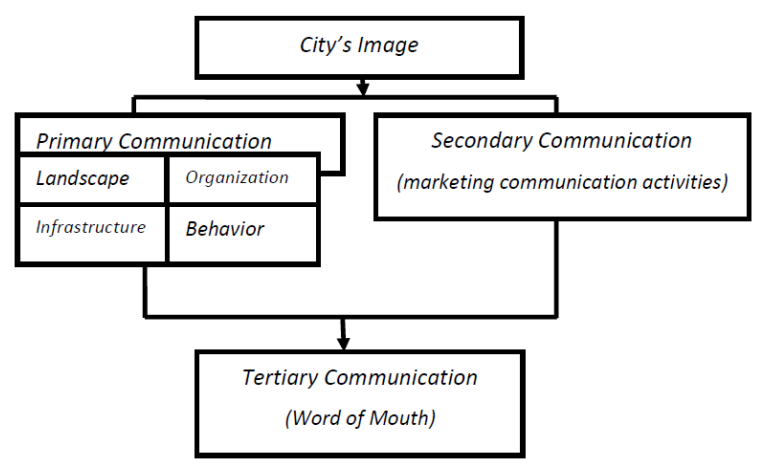

Gambar 1. City Branding Communication Model

Ada tiga sumber komunikasi menurut model ini adalah sebagai berikut:

\section{Primary Communication}

Merupakan efek komunikasi yang tercipta dari ciri fisik kota yang terdiri dari:

- Landscape, seperti desain kota, arsitektur, ruang hijau dan area publik bagi masyarakat kota.

- Infrastructure, yang terkait dengan akses dan fasilitas yang disediakan oleh suatu kota seperti, transportasi publik, jalan raya, bandara, pusat-pusat budaya dan sebagainya.

- Organization, terkait peran dan wewenang pemerintah daerah dalam kebijakan publik.

- Behavior, berhubungan dengan hal-hal yang unik yang menjadi daya tarik kota baik bagi penduduk setempat, turis maupun investor.

\section{Secondary Communication}

Aktivitas komunikasi pemasaran yang menonjolkan keunikan dan daya tarik kota, termasuk di dalamnya pemilihan teknik-teknik komunikasi seperti iklan, brosur, aktivitas humas pemasaran, penyelenggaraan event dan sebagainya.

\section{Tertiary Communication}

Aktivitas promosi getok-tular yang disampaikan oleh individu-individu yang memiliki sikap positif terhadap kota dan menyampaikan pada pihak lain atas kemauan sendiri.

Penelitian ini akan mengadopsi model di atas sebagai acuan untuk menganalisis proses komunikasi dalam pembentukkan city branding bagi Kota Banda Aceh.

\section{B. Multilateral Symmetrical Communication Model of City Branding}

Bicakci dan Genel (2016), dalam artikel mereka berjudul A Theoritical Approach for Sustainable Communication in City Branding mengembangkan model komunikasi yang lebih komprehensif dengan penekanan kepada interaksi di antara pemangku kepentingan. Menurut model ini, pemangku kepentingan dalam suatu kota saling berinteraksi satu sama lain baik secara langsung maupun tidak langsung. Proses dan hasil dari interaksi ini bersifat multilateral dan akan membentuk citra tertentu dari suatu kota.

Bicakci dan Genel (2016), membagi pemangku kepentingan menjadi dua kelompok, yaitu: kelompok Image Carrier (X) dan kelompok Organic Stakeholder (Y). Kelompok X ini menjadi pembawa (carrier) citra kota seperti, turis, pendatang, investor, penduduk setempat, civitas 
akademika kampus, sekolah, organisasiorganisasi non-profit dan lain-lain. Kelompok $X$ secara langsung maupun tidak langsung akan mengomunikasikan dan berbagi pandangan, pengalaman serta harapan dengan pihak lain mengenai kota dimana mereka beraktivitas. Dengan kata lain, Kelompok $X$ merepresentasikan merek suatu kota. Kelompok $Y$ adalah institusi atau organisasi yang dibentuk dan mewakili pihak pemerintah. Kelompok $Y$ ini melalui berbagai aktivitas merepresentasikan kepentingan kota, seperti pemerintah daerah setempat, walikota, bupati dan institusi-instutusi pelayanan pemerintah.

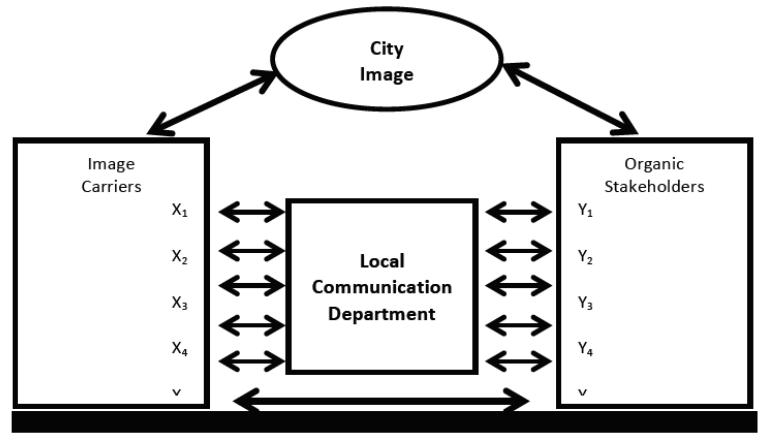

Gambar 2. Multilateral Symmetrical Communication Model of City Branding

(Sumber: Bicaki dan Genel, 2016)

Kedua kelompok ini saling berinteraksi dan hasilnya mempengaruhi pembentukan merek kota. Dalam upaya membentuk merek kota yang positif dan sesuai dengan keunikan yang dimiliki suatu kota, maka peran local communication department sangat besar untuk menciptakan dan mengelola merek kota. Dalam konteks Indonesia, local communication department adalah institusi kehumasan atau komunikasi publik yang ditugaskan oleh pemerintah untuk mengelola merek kota.

\section{Pendekatan Terintegrasi dalam Pemerekan Kota}

Penciptaan dan manajemen merek kota memerlukan upaya yang terintegrasi. Mengenai hal ini Kavaratzis (2004), mengemukakan perlunya mengadopsi konsep corporate branding untuk mengelola merek suatu kota melalui pendekatan terintegrasi delapan elemen kota:

1. Visi dan Strategi: Kejelasan mengenai pengembangan dan masa depan kota.

2. Kultur Internal: Seluruh upaya harus berorientasi kepada pengelolaan dan pengembangan merek kota dan aktivitas tersebut harus membudaya secara internal.

3. Komunitas Lokal: Memprioritaskan dan melibatkan penduduk lokal, wirausahawan dan pebisnis dalam mengembangkan merek kota.

4. Sinergi: Mengupayakan kesepakatan dan dukungan dari seluruh pemangku kepentingan terkait dalam rangka mengembangkan merek kota.

5. Infrastruktur: Menyiapkan infrastruktur standar yang memadai sesuai dengan merek kota yang sudah dicanangkan.

6. Lansekap kota: Menyiapkan lansekap kota sesuai dengan merek kota yang sudah dicanangkan. 
7. Peluang: Infrastruktur dan lansekap kota yang baik dapat menjadi stimulus dan daya tarik bagi pemangku kepentingan (pendatang, turis, pelaku bisnis, penduduk setempat).

8. Komunikasi: Merek kota dikomunikasikan secara stratejik dan berkesinambungan agar melekat di benak pemangku kepentingan dan menjadi identitas yang kuat dari suatu kota.

Namun demikian, berdasarkan UndangUndang No.15 tahun 2001 tentang Merek belum mengatur tentang city branding sebagai salah satu kelas dalam hak merek yang bisa didaftarkan di Direktorat Jenderal Hak Kekayaan Intelektual, dimana di dalam UU ini tidak ditemukan definisi dan ketentuan umum ataupun keterangan pada penjelasan Undang-Undang tersebut dengan menyebutkan city (Yuli, 2011).

\section{METODOLOGI KEGIATAN}

Kegiatan PkM ini berfokus dalam memberikan wawasan dan pengetahuan, serta keterampilan dalam menyusun strategi city branding yang menarik dan efektif melalui berbagai media untuk mengkomunikasikan citra Kota Banda Aceh. Penyampaian materi dilakukan dengan interaktif dengan format multimedia, dan rentang waktu tiga jam. Para pembicara dalam pelatihan ini adalah dosen-dosen Universitas Bakrie yang ahli di bidangnya. Peserta akan merasakan bagaimana berinteraksi dengan dosen yang handal, serta merasakan iklim belajar Universitas Bakrie yang terdiri dari berbagai pengetahuan dasar komunikasi dan city branding. Peserta juga dilibatkan langsung dalam penyusunan strategi city branding Kota Banda Aceh dan diskusi mengenai peran penting mempromosikan citra kota melalui berbagai media.

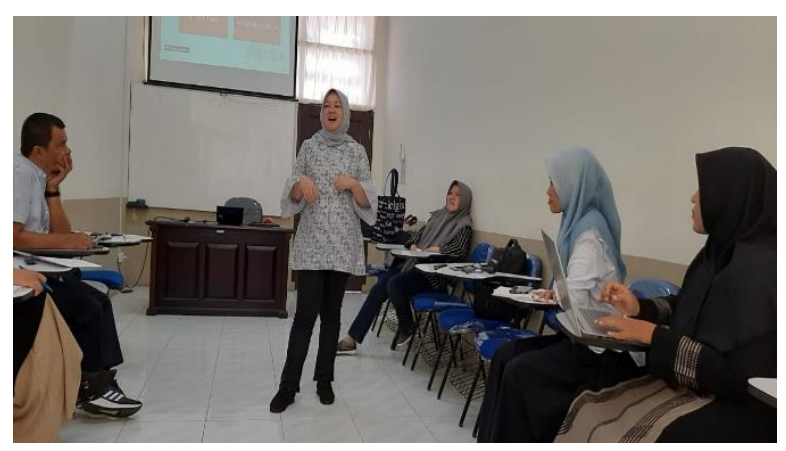

Gambar 3. Kegiatan Pelatihan Peningkatan Kapasitas Stakeholder dalam Menyusun Strategi

City Branding Kota Banda Aceh

(Sumber: dokumentasi penulis)

\section{HASIL DAN PEMBAHASAN}

Peserta kegiatan pelatihan berjumlah 6 orang, yang berasal dari media/wartawan (2 orang), Aparatur Sipil Negara dari Pemda Banda Aceh (2 orang), dan dari Lembaga Swadaya Masyarakat (2 orang). Materi pelatihan disampaikan menggunakan format multimedia yang diselingi interaksi langsung dengan peserta baik melalui tanya jawab, diskusi maupun praktik/simulasi. Materi pertama disampaikan dengan mengajak para peserta berdiskusi tentang potensi-potensi yang bisa dijadikan keunggulan Aceh yang meliputi destinasi wisata, kuliner, dan adat serta budaya Kota Banda Aceh yang berbeda dengan daerah lain.

Materi utama diberikan dengan memberikan pemahaman terlebih dahulu 
mengenai city branding. Peserta diminta untuk mengenali apa yang ada di media terkait branding Kota Banda Aceh. Terdapat berbagai tag line, logo yang tidak konsisten untuk branding Kota Banda Aceh di media. Bahkan peserta sendiri masih bingung dengan apa sebenarnya branding yang akan dikonstruksi dan dikampanyekan untuk Kota Banda Aceh. Beberapa media menyebut: Charming Aceh, The Light of Aceh dan Smart City Aceh. Ketika menilik pesan komunikasi mengenai identitas Kota Banda Aceh belum fokus pada konsep yang sama.

Dalam kegiatan pelatihan juga dijabarkan beberapa contoh terkait city branding, seperti strategi city branding yang dilakukan humas pemerintahan Kota Bandung melalui program Smart Governance (Ali, 2017), yang merupakan upaya Bandung menjadi salah satu smart city di Indonesia. Strategi city branding Pekalongan World's City of Batik (Susanti, 2018), juga menarik dimana Pekalongan menjadi kota dimana sebagaian besar penduduknya ada pebisnis dan pengrajin batik. Pengelolaan Branding Kota Samarinda yang dilakukan oleh Dinas Pariwisata Ekonomi Kreatif, Komunikasi dan Infromatika (Saputra, 2016), yang membuat Samarinda semakin dikenal sebagai salah satu kota besar di Kalimantan Timur. Apalagi saat ini ada dukungan infrastruktur bandara yang memadai, yang menjadikan Samarinda banyak dikunjungi wisatawan sekaligus pekerja tambang. Strategi membangun branding bagi pelaku usaha mikro kecil menengah (Setiawati, Retnasari, dan
Fritriawati, 2019), juga dijabarkan, mengingat dalam city branding, dukungan brand UMKM menjadi penting sebagai bagian yang terintegrasi dengan pariwisata daerah. Selain itu, peserta juga diberikan wawasan bagaimana city branding dapat meningkatkan kunjungan wisatawan mancanegara, dengan memberikan contoh kajian yang dilakukan Yulianto dan Mawardi (2016), mengenai peran city branding Kota Batu dalam trend peningkatan kunjungan wisatawan mancanegara. Pemerintah Daerah Kota Batu berhasil membangun image baru Kota Baru menjadi kota yang nyaman untuk wisata dan bisa berhasil meningkatkan kunjungan wisatawan mancangera dari tahun ke tahun. Selain itu kajian yang dilakukan Yuli (2011), mengenai city branding sebagai strategi pengembangan pariwisata ditinjau dari aspek hukum, dimana kasus yang dikaji adalah kasus di Daerah Istimewa Yogyakarta. Kajian ini disampaikan mengingat city branding menjadi trend baru sejak bergulirnya otonomi daerah, namun belum jelas payung hukum city brand yang menjadi produk kreatif terkait kekayaan intelektual pencipta brand.

Melihat keberagaman makna tentang city branding Kota Banda Aceh yang ada di media, ini menjadikan masyarakat Kota Banda Aceh sendiri perlu memiliki pemahaman mengenai identitas kotanya sendiri. Sebagai masyarakat dan ASN, peserta perlu tahu apa sebenarnya yang ingin dikontruksi oleh warga dan pemerintahnya mengenai branding Kota Banda Aceh. Identitas 
dan unsur keterkenalan Kota Banda Aceh perlu disusun dengan baik, sehingga mencapai kesamaan makna merek Kota Banda Aceh, bagi masyarakat dan pemerintah. Wartawan memberikan peran penting dalam menyuarakan city branding kotanya sendiri, baik bagi masyarakat Kota Banda Aceh khususnya dan masyarakat luas umumnya. Hal ini sejalan dengan riset yang dilakukan di Kabupaten Badung Bali dan Kota Solo, seperti yang dilakukan Bambang dan Setiansah (2014), dimana strategi pencitraan kota berbasis kearifan lokal dilakukan di dua wilayah tersebut. Solo dikenal dengan Spirit of Java, dan Kabupaten Badung dikenal dengan tri bita karana. Kota Banda Aceh harus menemukan kearifan lokalnya sendiri agar dapat mengembangkan brand-nya dengan kuat pada aspek internalisasi nilai-nilai lokal pada identitas kota.

Materi city branding memberikan pemahaman kepada peserta bahwa seluruh elemen perlu memberikan kontribusi pada upaya membangun identitas Kota Banda Aceh. Identitas adalah sebuah konstruksi, yakni konstruksi dari proses interaksi antar manusia, institusi dan praktis dalam kehidupan sosial masyarakat. City branding tidak dapat dipisahkan dari merek, karena city branding merupakan bagian dari konsep merek itu sendiri. Tujuan city branding adalah menciptakan citra dibenak masyarakat luas dalam merepresentasikan karakter kota. Merek yang melekat pada kota, bergantung pada identitas kota itu sendiri. Hal ini sejalan dengan kajian mengenai kaitan antara identitas kota dengan indeks kebahagiaan (Sukmadewi dan Novel, 2019). Berdasarkan kajian tersebut indeks kebahagiaan memiliki kaitan yang cukup kuat dengan keefektifan city branding. Clty branding yang efektif cenderung meningkatkan indeks kebahagiaan. Oleh karena itu, city branding melekat dengan tata kehidupan masyarakat Kota Banda Aceh sendiri.

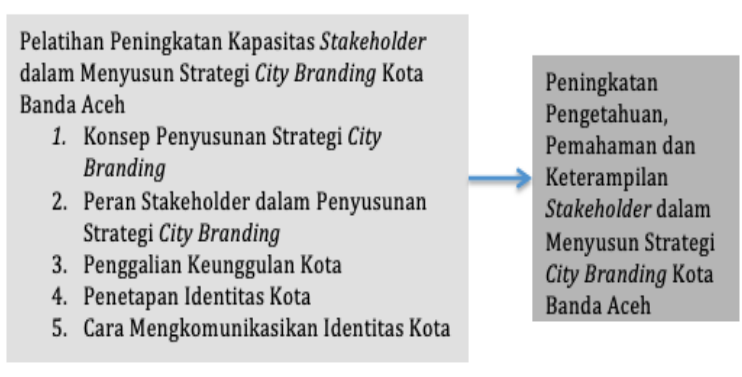

Gambar 4. Bagan Kegiatan PKM

Peserta juga diberikan pemahaman mengenai elemen-elemen penting dalam membangun city branding kota, yakni identitas, citra dan komunikasi yang harus terintegrasi, sehingga bisa tersampaikan pesan yang utuh dalam brand Kota Banda Aceh. Cara menonjolkan identitas kota adalah:

1. Menetapkan tujuan dan tujuan yang dapat diukur. Artinya city branding yang dilakukan harus didasarkan pada tujuan tertentu yang dapat diukur keberhasilannya.

2. Memahami target market. Pada umumnya city branding dilakukan untuk menarik market, baik pengunjung maupun investor untuk mendapatkan manfaat ekonomi dan kualitas hidup yang lebih baik bagi warganya. 
3. Mengidentifikasi brand image atau citra merek Kota Banda Aceh pada saat ini. Kota Banda Aceh yang dikenal dengan serambi Mekah dan sedang menggalakkan wisata halal, perlu menidentifikasi posisinya di dalam benak konsumen dan citra apa yang disematkan oleh masyarakat pada Kota Banda Aceh.

4. Berdasarkan hasil identifikasi citra kota saat ini, perlu ditetapkan positioning Kota Banda Aceh, sehinggal jelas posisinya bagai masyarakat.

5. Penetapan positioning Kota Banda Aceh akan menentukan strategi yang harus disusun agar di masa yang akan datang, jelas image yang akan disematkan pada Kota Banda Aceh.

Setelah city branding ditetapkan, yang perlu dilakukan kemudian adalah membuat brand Kota Banda Aceh dikenal luas. Informasi mengenai Kota Banda Aceh harus dapat diakses di media komunikasi manapun, media sosial dan media on line bisa membuat sebuah kota atau destinasi wisata jadi dikenal, menggunakan brand ambassador, dan warganya sendiri aktif mempromosikan kotanya di berbagai platform media.

\section{KESIMPULAN}

Kegiatan pengabdian kepada masyarakat yang berupa pelatihan peningkatan kapabilitas stakeholder dalam menyusun strategi city branding Kota Banda Aceh, menghasilkan kesimpulan sebagai berikut:
1. Peserta yang sebelumnya belum paham mengenai konsep-konsep dalam penyusunan strategi city branding setelah mengikuti pelatihan menjadi paham.

2. Peserta yang sebelumnya belum paham mengenai peran stakeholder, seperti media/ wartawan, ASN, dan LSM dalam berkontribusi untuk penyusunan strategi city branding setelah mengikuti pelatihan menjadi paham.

3. Peserta yang sebelumnya tidak mempunyai keterampilan dalam penyusunan strategi city branding untuk menggali keunggulan dan menetapkan identitas kota, citra dan komunikasinya setelah mengikuti pelatihan menjadi lebih terampil.

\section{SARAN}

Pelatihan berkaitan dengan peningkatan kapabilitas stakeholder dalam menyusun city branding perlu dilakukan sejak dini, khususnya bagi masyarakat terutama warga yang merupakan tokoh atau masyarakat terpelajar, mengingat posisinya sebagai agent of change yang aktif. Pelatihan ini juga sebaiknya dilakukan di kota-kota lain mengingat masih banyak kotakota di Indonesia yang belum menerapkan city branding dan belum maksimal dalam mengkomunikasikan kotanya

\section{UCAPAN TERIMA KASIH}

Penulis mengucapkan terima kasih sebesarbesarnya kepada Lembaga Pengabdian kepada Masyarakat Universitas Bakrie yang telah 
memberikan dukungan dana demi pelaksanaan kegiatan pengabdian kepada masyarakat.

\section{DAFTAR PUSTAKA}

Bicakci, A. B., dan Genel, Z. (2016). A Theoretical Approach for Sustainable Communication in City Branding Multilateral Symmetrical Communication Model. IGI Global Publisher of Timely Knowledge.

Hartono, E., Safitri, D. P., dan Kurnianingsih, F. (2019). Peran Pemerintah Daerah dalam Membangun City Branding di Kota Tanjung Pinang (Studi Kasus Kampung Pelangi). Spirit Publik, 14 (2), 103-110.

Kavaratzis, M. (2014). Rethinking Place Branding:

Comprehensive Brand Development for Cities and Regions. Switzerland: Springer.

López, F. J. M., Anaya, R., Aguilar, R., dan Molinillo, S. (2016). Online Brand Communities: Using the Social Web for Branding and Marketing. Switzerland: Springer.

Maulana, A. E. (2012). Mengubah Just Friend menjadi Soulmate. Jakarta: Etnomark Consulting.

Moilanen, T., dan Rainisto, S. (2009). How to Brand Nations, Cities an Destinations. Palgrave Macmillan.

Pramuningrum, A. D., dan Ali, D. S. F. (2017). Strategi City Branding Humas Pemerintahan Kota bandung sebagai Smart City melalui Program Smart Governance. Promedia, 3 (2), 162-182.
Saleh, R., dan Anisah, N. (2019). Pariwisata Halal di Aceh: Gagasan dan Realitas di Lapangan. Sahafa Journal of Islamic Communciation, 1 (2), 79-92.

Saputra, E. (2016). Peran Dinas Pariwisata Ekonomi Kreatif, Komunikasi dan Informatika dalam mengelola "Branding" Kota Samarinda. Jurnal IImu Komunikasi Universitas Mulawarman, 4 (2), 321-335.

Setiawati, S. D., Retnasari, M., dan Fitriawati, D. (2019). Strategi Membangun Branding bagi Pelaku Usaha Mikro Kecil Menengah. Jurnal Abdi Mas BSI, 2 (1), 125-136.

Subarkah, A. R., Rahman, J. B., dan Akim. (2020). Destination Branding Indoensia sebagai Destiansi Wisata Halal. Jurnal Kepariwisataan: Destinasi, Hospitalitas dan Perjalanan, 4 (2), 84-97.

Sukmadewi, R., dan Novel, N. J. A. (2019). Analisis Relevansi City Branding Kota Bandung Melalui Pendekatan Nilai Indeks Kebahagiaan. Reponsive, 2 (3), 83-93.

Sukmaraga, A. S., dan Nirwama, A. (2016). City Branding: Sebuah Tinjuan Metodologis dengan Pendekatan Elaboratif, Praktis, dan Ilmiah. Journal of Art, Dedsign, Art Education \& Cultural Studies, 1 (1), 1-19.

Susanti, R. A. (2018). Strategi City Branding Pekalongan "World's City of Batik". Jurnal Seni Budaya, 16 (1), 96-110.

Widodo, B., dan Setiansah, M. (2014). Strategi Pencitraan Kota (City Branding) Berbasis Kearifan Lokal (Studi Kasus di Kota Solo, Jawa 
Indonesian Journal for Social Responsibility (IJSR) Vol. 2, No. 02, (2020), hal. 81-92

Tengah dan Kabupaten Badung Bali). Jurnal Profetik, 7 (2), 33-44.

Yuli, A. (2011). City Branding sebagai Strategi Pengembangan Pariwisata ditinjau dari Aspek Hukum Merek (Study Kasus City
Branding Daerah Istimewa Yogyakarta sebagai Daerah Tujuan Wisata Unggulan di Indonesia). Jurnal IImiah IImu Hukum QISTI, $5(1), 50: 68$. 